\title{
Finding needles in a haystack
}

DOI:

10.1038/nrc2177

\section{URLs}

FGFR2

http://www.ncbi.nlm.nih.gov/ sites/entrez?Db=gene\&Cmd= ShowDetailViewยTermToSearc $\mathrm{h}=2263$

\section{TNRC9}

http://www.ncbi.nlm.nih.gov/ sites/entrez? Db=gene\&Cmd= ShowDetailView\&TermToSearc $\mathrm{h}=27324$

\section{MAP3K1}

http://www.ncbi.nlm.nih.gov/ sites/entrez? $\mathrm{Db}=$ gene\&Cmd= ShowDetailView\&TermToSearc $h=4214$

LSP1

http://www.ncbi.nlm.nih.gov/ sites/entrez? $\mathrm{Db}=$ gene\&Cmd= ShowDetailView\&TermToSearc $\mathrm{h}=4046$
Less than $25 \%$ of the genes that account for the familial risk of breast cancer have been identified, and genetic variants contributing more moderate risk probably explain much of the remaining $75 \%$. A recent publication in Nature and two in Nature Genetics have identified several new breast cancer susceptibility loci using genome-wide association studies.

Douglas Easton and colleagues began with a panel of 266,722 single nucleotide polymorphisms (SNPs), and identified the 12,711 that were most significantly different between 390 cases of familial breast cancer and 364 controls from the UK. These SNPs were examined in an additional 3,990 cases and 3,916 controls, and the 30 most significant SNPs were genotyped in 21,860 cases of invasive breast cancer, 988 cases of carcinoma in situ and 22,578 controls from 22 studies. Six of these SNPs had a significance of $\leq 10^{-5}$, and five fell within genes or linkage disequilibrium (LD) blocks containing genes. One was within an intron of fibroblast growth factor receptor 2 (FGFR2), a receptor tyrosine kinase that is amplified and overexpressed in breast cancer. Two fell in an LD block containing the 5' end of trinucleotide repeat containing 9 (TNRC9), a member of the highmobility group family of chromatin proteins. A fourth lay within another LD block containing mitogen-activated protein kinase kinase kinase 1 (MAP3K1), and the fifth SNP was in an intron of lymphocyte-specific protein 1 (LSP1), an F-actin binding and cytoskeleton-associated protein. The sixth SNP was in a region on chromosome 8 with no known genes, but was close to other loci known to be important in prostate cancer.
David Hunter and colleagues analysed the genotypes of 528,173 SNPs in 1,145 cases of invasive breast cancer in Caucasian women and 1,142 controls from the Nurses' Health Study. The two most significant SNPs were, as in the study by Easton and colleagues, in intron 2 of FGFR2. This result was verified in an additional 1,776 cases and 2,072 controls from three other prospective cohorts. Both studies indicate that there is a breast cancer susceptibility locus in FGFR2, but further work is needed to identify the causal variant.

Simon Stacey, Kari Stefansson and colleagues examined 311,524 SNPs in 1,600 Icelandic patients with breast cancer and 11,563 controls, and the 10 SNPs with the lowest $P$ values were genotyped in up to five additional sample sets from Iceland, Sweden, Spain, The Netherlands and the United States. In all five sets, two SNPs conferred increased risk of breast cancer: one on chromosome 2q35 and one on $16 q 12$. These two alleles were also specifically associated with the risk of oestrogen-receptor-positive breast cancer. No genes in the region containing the 2q35 SNP are known. The SNP on $16 \mathrm{q} 12$ is near the $5^{\prime}$ end of TNRC9, one of the genes identified by Easton and colleagues.

These studies have furthered our understanding of the genetics of breast cancer risk, and additional susceptibility alleles might also be identified using this type of approach. Sarah Seton-Rogers

ORIGINAL RESEARCH PAPERS Easton, D. F. et al. Genome-wide association study identifies novel breast cancer susceptibility loci. Nature 27 May 2007 (doi: 10.1038/nature05887)| Hunter, D. et al. A genome-wide association study identifies alleles in FGFR2 associated with risk of sporadic postmenopausal breast cancer. Nature Genet. 27 May 2007 (doi: 10.1038/ng2075)| Stacey, S. N. et al. Common variants on chromosomes $2 \mathrm{q} 35$ and $16 \mathrm{q} 12$ confer susceptibility to estrogen receptor-positive breast cancer. Nature Genet. 27 May 2007 (doi: 10.1038/ng2064) WEB SITE http://cgems.cancer.gov

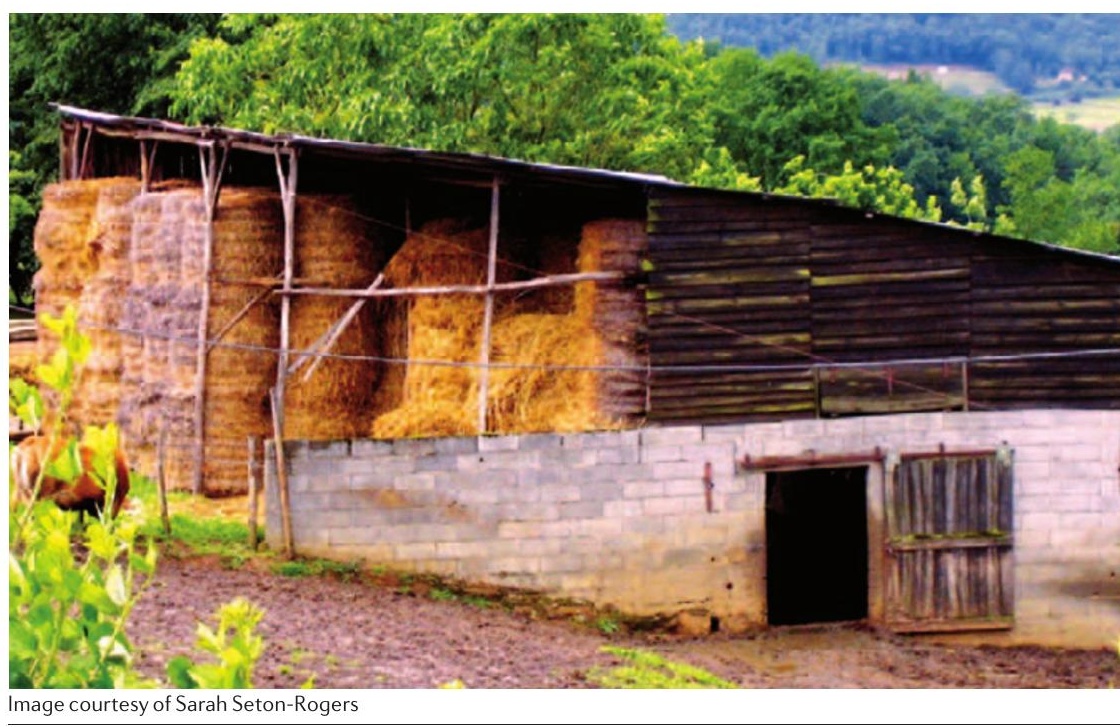

